\title{
Dynamic respiratory system mechanics in infants during pressure and volume controlled ventilation
}

\author{
V. Kessler*, J. Guttmann*, C.J.L. Newth"
}

\begin{abstract}
Dynamic respiratory system mechanics in infants during pressure and volume controlled ventilation. V. Kessler, J. Guttmann, C.J.L Newth. C) ERS Journals Ltd 2001.

ABSTRACT: Dynamic respiratory system mechanics can be determined using multiple linear regression (MLR) analysis. There is no need for a particular ventilator setting or for a special ventilatory manoeuvre. The purpose of this study was to investigate whether or not different ventilator modes and the flow-dependent resistance of the endotracheal tube (ETT) influence the determination of resistance and compliance by MLR.

Ten paediatric patients who were on controlled mechanical ventilation for various disorders were investigated. The ventilator modes were changed between pressure control (PC) and volume control (VC). Flow and airway pressure were measured and tracheal pressure was continuously calculated. Each mode was applied for $3 \mathrm{~min}$, and 10 consecutive breaths at the end of each period were analysed. Respiratory mechanics were determined by MLR based on either airway pressure, thus including the resistance of the ETT, or tracheal pressure.

Resistance was found to be slightly higher in PC than in VC. There was no effect on determination of compliance between the different modes. Elimination of the flowdependent resistance of the ETT preserved the differences between the modes.

The authors conclude that using multiple linear regression compliance is not affected by the actual ventilator mode, whereas resistance is.

Eur Respir J 2001; 17: 115-121.
\end{abstract}

*Section of Experimental Anesthesiology, Dept of Anesthesiology and Critical Care Medicine, University of Freiburg, Germany and ${ }^{\#}$ Division of Pediatric Critical Care, Children's Hospital of Los Angeles, University of Southern California School of Medicine, Los Angeles, CA, USA.

Correspondence: V. Kessler, Sektion Experimentelle Anästhesiologie, Anästhesiologische Universitätsklinik Freiburg, Hugstetter Str. 55, 79106 Freiburg, Germany. Fax: 49761270 2396

Keywords: Compliance, endotracheal tube, mechanical ventilation, multiple linear regression, resistance, tracheal pressure

Received: November 251999

Accepted after revision September 15 2000
Sophisticated analysis of respiratory mechanics has been proposed for mechanically ventilated infants and children in the intensive care unit [1]. During each analysis, the physician at the bedside can assess pulmonary state and course, by evaluating respiratory system resistance $(R \mathrm{rs})$ and/or compliance $(C \mathrm{rs})$ [2]. The effects of bronchodilators and other treatments can also be assessed [3], and the ventilator settings can be adjusted with respect to the actual mechanical state of the patient's lung $[4,5]$ in order to minimize the mechanical stress for the patient's lung, and to prevent ventilator associated lung injury [6-8]. Thus, for respiratory monitoring, the physician at the bedside has to obtain $R$ rs and $C$ rs easily and quickly, preferably on-line. Multiple linear regression (MLR) analysis is a method for analysis of pulmonary mechanics, that does not require any special ventilator setting or manoeuvre. However, the respiratory system must be passive, since the pressure generated by respiratory muscle activity cannot be predicted. The parameters $R$ rs and $C$ rs are determined by solving the equation of motion of the passive respiratory system by least square fitting, using the continuously measured samples of pressure, flow, and volume [9-12]. The advantages of MLR are obvious: 1) there are no cumbersome or time-consuming manoeuvres to perform; 2) MLR permits simulta- neous determination of both $C$ rs and $R \mathrm{rs} ; 3$ ) parameters can be determined on-line, on a breath-by-breath basis, without changing the actual ventilator setting during ongoing mechanical ventilation.

However, as the method uses all data points sampled during one breath and as different ventilator modes produce different flow-, pressure-, time-relationships, it was hypothesized that the obtained values for respiratory mechanics might be dependent on the mode of ventilation. Furthermore, there is the strongly flowdependent high resistance of the paediatric endotracheal tube (ETT) [13-15] which may influence the determination of respiratory system mechanics.

The purpose of this study was to identify the influence of the ventilator mode, and of the ETT, on the analysis of dynamic respiratory system mechanics using the MLR-method in paediatric patients under controlled mechanical ventilation.

\section{Methods}

The study was approved by the Committee on Clinical Investigations of the Children's Hospital, Los Angeles. Informed consent for participation in the study was obtained from the parents or guardians of each child. 


\section{Study design}

The authors studied 10 children on controlled mechanical ventilation in the paediatric intensive care unit (ICU) of the Children's Hospital, Los Angeles. The patients were ventilated either for obstructive diseases, for acute respiratory distress syndrome (ARDS), or for nonpulmonary diseases such as head injury. Patient characteristics are summarized in table 1.

All patients were intubated transorally using cuffed ETTs [16], with internal diameters (IDs) ranging from $3.0-4.5 \mathrm{~mm}$. The patients were sedated with midazolam $\left(0.1 \mathrm{mg} \cdot \mathrm{kg}^{-1}\right.$ i.v. $)$ and morphine $\left(0.1 \mathrm{mg} \cdot \mathrm{kg}^{-1} i . v\right.$. $)$, paralysed with vecuronium $\left(0.1 \mathrm{mg} \cdot \mathrm{kg}^{-1}\right)$, and were placed in the supine position. The ETT cuff was inflated to eliminate air leak at peak inspiratory pressure. The patients were ventilated with a Servo 300 ventilator (Siemens-Elema, Solna, Sweden) in the pressure controlled mode. Ventilator settings were chosen by the intensivist in charge of the patient's care. Secretions were suctioned preceding each investigation. For the period of investigation, the ventilator modes were changed between pressure control (PC) and volume control (VC). Minute ventilation ( $\left.V^{\prime} \mathrm{E}\right)$, positive endexpiratory pressure (PEEP), inspiratory time $(t \mathrm{I})$, and respiratory frequency $(f \mathrm{R})$ were kept constant throughout the different ventilator modes.

Each ventilator mode was applied for $3 \mathrm{~min}$. Flow and airway pressure $(P$ aw $)$ were continuously measured (Bicore Neonatal Pulmonary Monitor, CP 100 N, Bicore, Irvine, CA, USA) using a VarFlex-flow transducer (Bicore, Irvine, CA, USA) placed between the proximal end of the ETT and the Y-piece of the ventilator tubing. Since the Bicore pulmonary monitor does not consider the flow-dependent effects of the ETT in its on-line determination of respiratory system mechanics, the authors did not focus on these data. Data were sampled at $100 \mathrm{~Hz}$ and transmitted to a standard laptop personal computer for further analysis. Flow and $P$ aw were checked for artifacts, the flow signal was integrated to obtain volume, and tracheal pressure ( $P$ trach) was continuously calculated by subtracting the flow-dependent pressure drop across the ETT from $P$ aw $[17,18]$. Using this mathematical determination of $P$ trach the inertance of the ETT has been considered. Dynamic respiratory system mechanics were deter- mined by MLR based on the equation of motion of the passive respiratory system $[9,10]$ :

$$
P(\mathrm{t})=(1 / C) \times V(\mathrm{t})+R \times V^{\prime}(\mathrm{t})+P_{0}
$$

Pressure $(P)$ equals the sum of an elastic pressure component (volume $(V)$ divided by compliance $(C)$ ), a resistive pressure component (resistance $(R) \times$ flow), and a pressure $(P 0$; being the end-expiratory alveolar pressure) $[19,20]$. A prerequisite for valid determination of $R, C$, and $P_{0}$ is a good fit of the model to the data.

Depending on the pressure $P$ aw or $P$ trach in the equation of motion, the interpretation of the parameters $R$ and $C$ is different [21]. Using airway pressure for the fit procedure, the parameters $R$ and $C$ not only describe resistance and compliance of the respiratory system ( $C$ rs and $R \mathrm{rs}$ ), they describe the sum of the ETT impedance and of the respiratory system impedance: $R$ rs,tot and $C$ rs,tot. However, when using $P$ trach for the fit procedure, the parameters $R$ and $C$ describe the mere resistance and compliance of the respiratory system Rrs,corr and $C$ rs,corr.

Based either on the measured $P$ aw (thus including ETT-resistance) or on the calculated $P$ trach (thus excluding ETT-resistance), 10 consecutive breaths towards the end of the period of each ventilator mode were analysed. At this time no changes between consecutive breaths were detectable, i.e. it can be reasonably assumed that the respiratory system was in steady state conditions and temporary effects due to the change from the one mode to the other, had ceased. At the end of the study, the ventilator was reset to the initial mode (PC).

The same 10 breaths were analysed with respect to inspiratory and expiratory respiratory system mechanics using MLR. As expiration is independent of the actual ventilator mode, no differences between the expiratory mechanics during PC or VC ventilation were expected.

To test the inter-breath reproducibility of the respiratory mechanics parameters, the coefficient of variation was determined. Differences in the respiratory mechanics indices $R$ and $C$ between the modes were tested using the paired Wilcoxon test and p-values $<0.05$ were considered to indicate statistical significance. To test the quality of fit for each ventilator mode

Table 1. - Patient characteristics

\begin{tabular}{lccll}
\hline $\begin{array}{l}\text { Infant } \\
\text { no. }\end{array}$ & $\begin{array}{c}\text { BW } \\
\mathrm{kg}\end{array}$ & $\begin{array}{c}\text { Age at } \\
\text { study }\end{array}$ & Sex & Diagnoses \\
\hline 1 & 9.6 & 23 months & $\mathrm{M}$ & Status asthmaticus \\
2 & 3 & 51 days & $\mathrm{F}$ & Central hypoventilation syndrome \\
3 & 10 & 24 months & $\mathrm{M}$ & ARDS, gangliosidosis \\
4 & 12 & 3 yrs 9 months & $\mathrm{F}$ & ARDS \\
5 & 11.2 & 19 months & $\mathrm{M}$ & Severe head injury, no lung disease \\
6 & 9 & 14 months & $\mathrm{F}$ & Pneumonia and ARDS \\
7 & 5.2 & months & $\mathrm{M}$ & Total anomalous pulm. venous return \\
8 & 3.4 & 2 days 3 months & $\mathrm{M}$ & Bronchiolitis \\
9 & 14.8 & 12 months & $\mathrm{M}$ & Status asthmaticus, chronic lung disease \\
10 & 6.9 & Acute-on-chronic lung disease & \\
\hline
\end{tabular}

BW: body weight; M: male; F: female; ARDS: acute respiratory distress syndrome; pulm.: pulmonary. 
applied, $P$ aw and $P$ trach were recalculated point by point according to the equation of motion (see above), using the previously determined values for $R, C$, and $P 0$ and the measured values for flow and volume. The root mean squares (RMS) deviation between the "real" and the recalculated pressure was determined [22]. RMS is a quantitative indicator for the quality of the fit. The lower the RMS value, the better the quality of the fit. An RMS value of $1 \mathrm{cmH}_{2} \mathrm{O}$ means a mean deviation between all measured and recalculated pressure samples of $1 \mathrm{cmH}_{2} \mathrm{O}$, whereas an $\mathrm{RMS}$ value of zero would indicate a perfect fit.

\section{Results}

The ventilator settings for each patient and for each ventilator mode are summarized in table 2. Figure 1 shows the flow, volume, and airway and tracheal pressure curves at the two different ventilator modes in one representative patient (table 1, patient no. 2). Also shown are the recalculated airway and tracheal pressure curves (dashed lines, $P$ aw MLR and Ptrach MLR, respectively). Measured and recalculated pressures are in agreement (low RMS values), indicating a good quality of fit. However, differences between the modes are obvious: the decelerating flow and constant pressure pattern in PC mode versus the constant flow and linearly increasing pressure curve in VC mode. Furthermore, the peak inspiratory flow rate in $\mathrm{PC}$ mode is almost twice as high as that in VC mode.

Figures 2 and 3 show the results from the determination of resistance and compliance, based on either $P$ aw or $P$ trach, respectively. Each symbol represents the mean of 10 breaths for each individual patient. All parameters showed a high inter-breath reproducibility with a coefficient of variation $<4 \%$. Also shown are mean values of all patients (bold line in each diagram). Mean differences in resistance between $\mathrm{PC}$ and $\mathrm{VC}$ modes were $7.5 \mathrm{cmH}_{2} \mathrm{O} \cdot \mathrm{s} \cdot \mathrm{L}^{-1}$ (fig. $2, \mathrm{p}=0.0051$ ) and 6.5 $\mathrm{cmH}_{2} \mathrm{O} \cdot \mathrm{s} \cdot \mathrm{L}^{-1}$ (fig. 2, $\mathrm{p}=0.0284$ ) for MLR, based on $P$ aw and $P$ trach respectively. These differences are approximately 8 and $9 \%$ of the absolute value of $R$ rs,tot and Rrs,corr. Elimination of the flow-dependent resistance of the ETT did lower the absolute value of
$R$ rs,tot, as expected, but also preserved the statistically significant difference in $R$ rs,corr between the PC and VC ventilator modes. There was no statistically significant effect on the determination of $C_{\text {rs, tot }}$ between the different modes. Furthermore, there was no ETT related effect on the determination of $C$ rs,corr.

As expected, there was no statistically significant difference between the expiratory mechanics of the PCand the VC-ventilator modes. Based on $P$ aw, expiratory $R$ rs,tot, (mean $\pm \mathrm{SD})$ was $91.1 \pm 34.8 \mathrm{cmH} \mathrm{C}_{2} \mathrm{O} \cdot \mathrm{s} \cdot \mathrm{L}^{-1}$ (PC) versus $88.9 \pm 32.1 \mathrm{cmH}_{2} \mathrm{O} \cdot \mathrm{s} \cdot \mathrm{L}^{-1}$ (VC). Based on Ptrach, expiratory $R \mathrm{rs}$,corr was $67.5 \pm 29.3 \mathrm{cmH} \mathrm{CH}_{2} \mathrm{O} \cdot \mathrm{s} \cdot \mathrm{L}^{-1}$ (PC) versus $66.0 \pm 27.3 \mathrm{cmH}_{2} \mathrm{O} \cdot \mathrm{s} \cdot \mathrm{L}^{-1}$ (VC). Regarding the inspiratory mechanics, there was a statistically significant difference between the PC- and the VC-ventilator mode. Based on $P$ aw, inspiratory $R$ rs, tot was $80.2 \pm$ $32.3 \mathrm{cmH}{ }_{2} \mathrm{O} \cdot \mathrm{s} \cdot \mathrm{L}^{-1}(\mathrm{PC})$ versus $59.5 \pm 35.2 \mathrm{cmH}_{2} \mathrm{O} \cdot \mathrm{s} \mathrm{L}^{-1}$ (VC), $\mathrm{p}=0.0166$. Based on $P$ trach, inspiratory $R$ rs,corr was $63.3 \pm 26.9 \mathrm{cmH} \mathrm{C}_{2} \mathrm{O} \cdot \mathrm{s} \cdot \mathrm{L}^{-1}$ (PC) versus $50.2 \pm 27.7$ $\mathrm{cmH}_{2} \mathrm{O} \cdot \mathrm{s} \cdot \mathrm{L}^{-1}(\mathrm{VC})$. However, two patients had to be excluded due to considerable nonlinearity of the inspiratory limb of the dynamic $P V$-loop (patient nos. 3 and 6 , table 2). Therefore, the differences in inspiratory $R$ rs,corr did not reach statistical significance. When separating inspiration and expiration, no significant differences between PC and VC were found for $C$ rs,tot and $C$ rs,corr.

The mean resistance of the ETT, over the total flow range of a breath, was $30 \mathrm{cmH}{ }_{2} \mathrm{O} \cdot \mathrm{s} \cdot \mathrm{L}^{-1}(3.0 \mathrm{~mm}$ ID), $27 \mathrm{cmH}_{2} \mathrm{O} \cdot \mathrm{s} \cdot \mathrm{L}^{-1}\left(3.5 \mathrm{~mm}\right.$ ID), $17 \mathrm{cmH}_{2} \mathrm{O} \cdot \mathrm{s} \cdot \mathrm{L}^{-1}(4.0 \mathrm{~mm}$ ID), and $12 \mathrm{cmH}{ }_{2} \mathrm{O} \cdot \mathrm{s} \cdot \mathrm{L}^{-1}(4.5 \mathrm{~mm}$ ID). Regarding the quality of fit, the RMS between the airway or tracheal pressure and the recalculated airway or tracheal pressure within each ventilator mode were $1.27 \pm 0.45 \mathrm{cmH}_{2} \mathrm{O}(\mathrm{PC})$ versus $1.02 \pm 0.55 \mathrm{cmH}_{2} \mathrm{O}(\mathrm{VC})$ for MLR based on $P$ aw, and $1.27 \pm 0.49 \mathrm{cmH}_{2} \mathrm{O}$ (PC) versus $1.04 \pm 0.60 \mathrm{cmH}_{2} \mathrm{O}$ (VC) for MLR based on $P$ trach. On average, RMS was below $5 \%$ of peak inspiratory pressure (PIP) in both modes (table 2). The RMS values indicate a good quality of fit in each mode allowing a comparison of the respiratory mechanics indices between the modes. The quality of fit is slightly better in the VC mode compared with the PC mode. However, it is noteworthy that there was no improvement in the quality of fit after elimination of the

Table 2. - Ventilator settings for pressure controlled (PC)/volume controlled (VC) modes

\begin{tabular}{lccccccccccc}
\hline $\begin{array}{l}\text { Infant } \\
\text { no. }\end{array}$ & $\begin{array}{c}\text { ETT } \\
\text { mm ID }\end{array}$ & $\begin{array}{c}\mathrm{LMV} \\
\text { days }\end{array}$ & $F \mathrm{I}, \mathrm{O}_{2}$ & $\begin{array}{c}\mathrm{PIP}^{*} \\
\mathrm{cmH}_{2} \mathrm{O}\end{array}$ & $\begin{array}{c}\mathrm{PEEP} \\
\mathrm{cmH}_{2} \mathrm{O}\end{array}$ & $\begin{array}{c}\mathrm{Mean} P \mathrm{aw}^{*} \\
\mathrm{cmH}_{2} \mathrm{O}\end{array}$ & $\begin{array}{c}V^{\prime} \mathrm{E}^{*} \\
\mathrm{~L} \cdot \mathrm{min}^{-1}\end{array}$ & $\begin{array}{c}t \mathrm{I} \\
\mathrm{s}\end{array}$ & $\begin{array}{c}f_{\mathrm{R}} \\
\mathrm{min}^{-1}\end{array}$ & $\begin{array}{c}\text { Mean } V^{\prime \text { insp* }} \\
\mathrm{mL} \cdot \mathrm{s}^{-1}\end{array}$ & $\begin{array}{c}\text { Mean } V^{\prime} \text { exp* } \\
\mathrm{mL} \cdot \mathrm{s}^{-1}\end{array}$ \\
\hline 1 & 3.5 & 5 & 0.35 & $35 / 44$ & 10 & $16 / 16$ & $3.0 / 3.1$ & 0.8 & 20 & $149 / 152$ & $55 / 55$ \\
2 & 3.0 & 3.5 & 0.35 & $18 / 21$ & 2 & $6 / 5$ & $1.2 / 1.2$ & 0.75 & 22 & $45 / 43$ & $17 / 17$ \\
3 & 4.0 & 10 & 0.95 & $38 / 42$ & 10 & $22 / 18$ & $3.1 / 3.3$ & 1.2 & 22 & $84 / 96$ & $73 / 70$ \\
4 & 4.5 & 15 & 0.7 & $38 / 44$ & 12 & $24 / 20$ & $3.6 / 3.7$ & 1.2 & 25 & $96 / 110$ & $98 / 95$ \\
5 & 4.5 & 9 & 0.3 & $26 / 30$ & 4 & $10 / 9$ & $2.6 / 2.6$ & 0.7 & 18 & $202 / 197$ & $57 / 56$ \\
6 & 4.0 & 9 & 0.5 & $40 / 44$ & 10 & $19 / 15$ & $2.2 / 2.3$ & 0.9 & 20 & $89 / 84$ & $39 / 35$ \\
7 & 3.5 & 15 & 0.6 & $29 / 34$ & 6 & $11 / 9$ & $2.2 / 2.4$ & 0.6 & 20 & $123 / 121$ & $28 / 29$ \\
8 & 3.0 & 11.5 & 1 & $24 / 27$ & 8 & $12 / 11$ & $1.0 / 1.1$ & 0.65 & 25 & $28 / 23$ & $10 / 13$ \\
9 & 4.0 & 8.5 & 0.6 & $34 / 40$ & 4 & $12 / 11$ & $2.9 / 3.0$ & 0.8 & 20 & $132 / 125$ & $50 / 47$ \\
10 & 4.0 & 5 & 0.4 & $22 / 26$ & 4 & $8 / 8$ & $1.8 / 1.9$ & 0.7 & 20 & $86 / 81$ & $28 / 26$ \\
\hline
\end{tabular}

ETT: endotracheal tube; ID: internal diameter; LMV: length of mechanical ventilation; $F \mathrm{I}, \mathrm{O}_{2}$ : fraction of inspired oxygen; PIP: peak inspiratory pressure; PEEP: positive end-expiratory pressure; mean $P$ aw: mean airway pressure; $V^{\prime} E$ : minute ventilation; $t \mathrm{I}$ : inspiratory time; $f \mathrm{R}$ : respiratory frequency; mean $V^{\prime}$ insp: mean inspiratory flow; $V^{\prime}$ exp: mean expiratory flow. *: values for PCl VC. 
a) 0.15

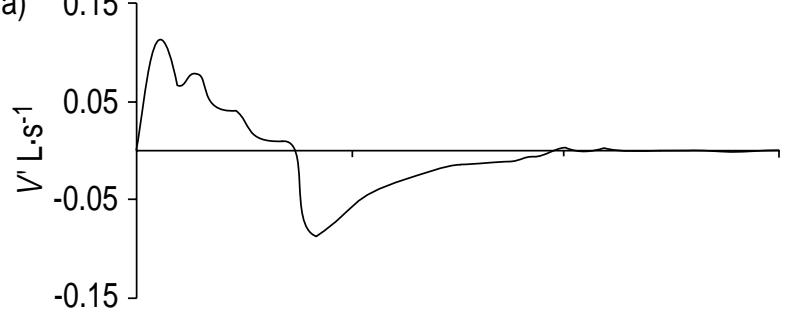

C)

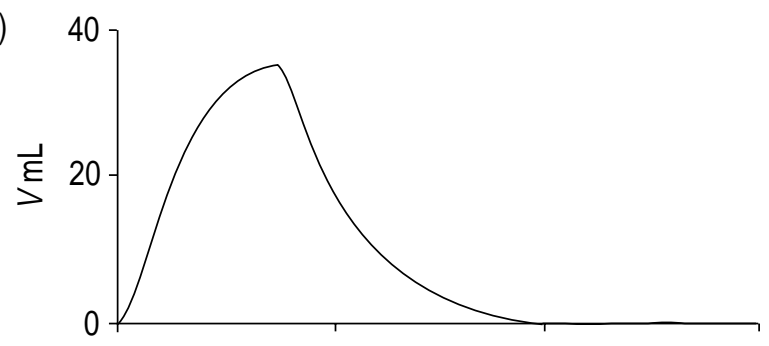

e)
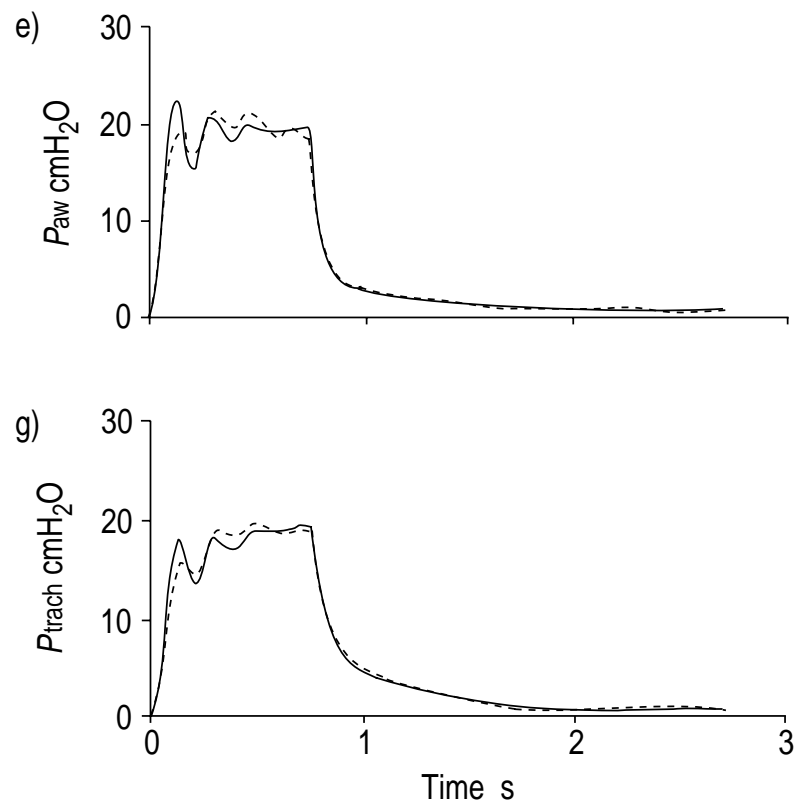

b)

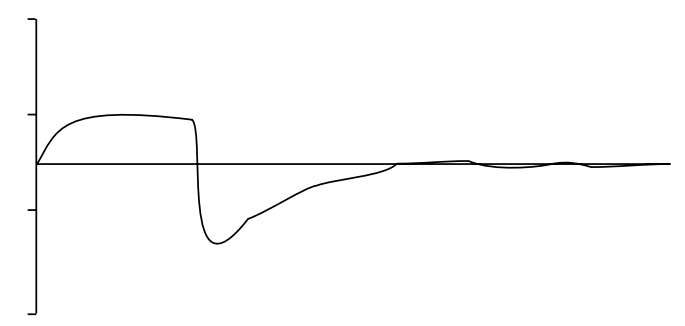

d)

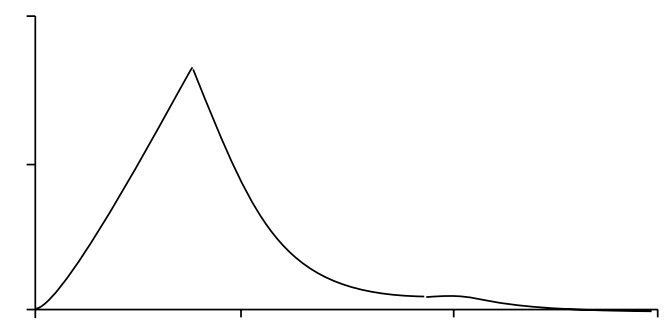

f)

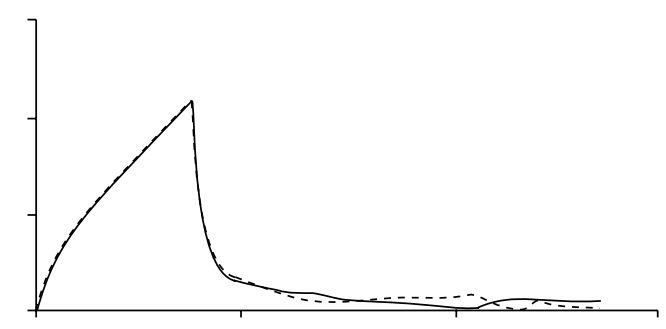

h)

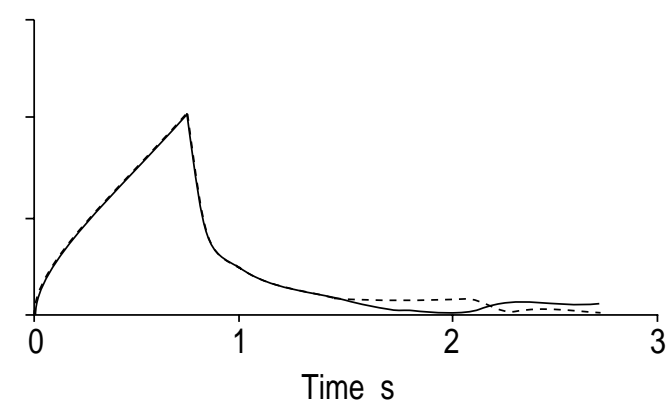

Fig. 1. - a) and b) inspiratory flow $\left(V^{\prime}\right)$, c) and d) tidal volume $(V)$, e) and f) airway pressure $(P$ aw $)$, and g) and h) tracheal pressure (Ptrach) curves in two different ventilator modes: pressure control (PC, a, c, e, g) and volume control (VC, b, d, f, h) in patient no. 2. Also shown are the recalculated airway and tracheal pressure curves, i.e. the best fit to the observed pressure by the linear resistancecompliance-model (dashed lines $P$ aw-MLR and $P$ trach-MLR, respectively). The root mean squares (RMS) deviations between measured and recalculated airway and tracheal pressures are given as a measure of the quality of fit and are as follows: e) $\mathrm{RMS}=0.95 \mathrm{cmH} \mathrm{O}_{2} \mathrm{O}$; f) $\mathrm{RMS}=0.75 \mathrm{cmH}_{2} \mathrm{O}$; g) $\mathrm{RMS}=0.80 \mathrm{cmH}_{2} \mathrm{O}$; and h) $\mathrm{RMS}=0.73 \mathrm{cmH}_{2} \mathrm{O}$. MLR: multiple linear regression.

flow-dependent resistance of the ETT both in the PC and in the VC modes.

\section{Discussion}

The main finding of this study is that in paediatric patients under controlled mechanical ventilation, determination of dynamic respiratory system mechanics by MLR yields significantly different values for resistance depending on the ventilator mode applied, whereas compliance is not influenced by the ventilator mode.
This finding is also preserved after elimination of the flow-dependent resistance of the ETT.

As shown in figure 1, the inspiratory flow and pressure curves differ considerably, depending on the ventilator mode applied. The MLR method allows determination of dynamic respiratory system mechanics without interfering with actual ventilation and, therefore, describes the lung in its actual state. MLR determines resistance, compliance and the endexpiratory alveolar pressure, by taking into consideration each sampled point of flow, volume, and pressure. Therefore, by using all data points of a breath, MLR has to determine the inherent resistance and 


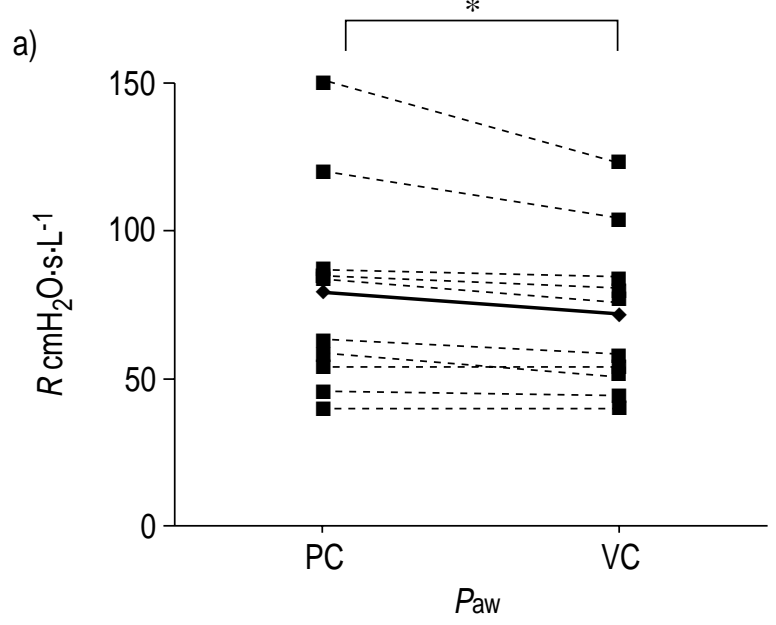

b)

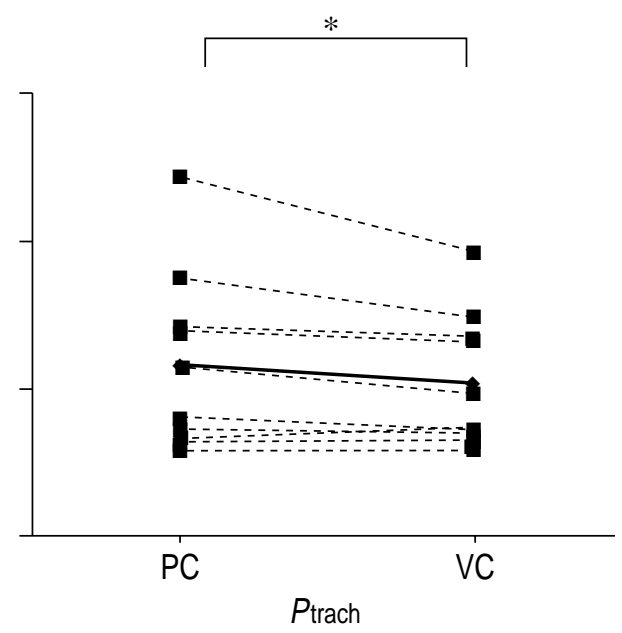

Fig. 2. - Differences in the determination of resistance during the different ventilator modes for individual infants. Symbols represent the mean out of 10 breaths. SD was generally less than $2 \%$ of the absolute value of respiratory system resistance $(R \mathrm{rr})$ and, therefore, is not shown. a) Resistance is determined by multiple linear regression (MLR) based on airway pressure ( $P$ aw), thus including the endotracheal tube (ETT); b) MLR is based on tracheal pressure (Ptrach), thus excluding ETT. Bold lines indicate mean values for all infants. PC: pressure controlled mode; VC: volume controlled mode; *: $\mathrm{p}<0.05$.

compliance, independent of the actual ventilator mode, i.e. independent of different flow- and pressure-profiles within PC- or VC-ventilation.

Varying the actual position on the pressure-volume curve of the respiratory system may result in a change of respiratory system mechanics. In order to avoid a change of the actual position on the $P V$-curve, PEEP, $V \mathrm{I}, t \mathrm{I}$, and $f \mathrm{R}$ were kept constant. This resulted in higher peak inspiratory pressure values in $\mathrm{VC}$, as shown in table 2 . These values can be explained by the fact that flow and, therefore, a resistive pressure contribution, are present until the end of inspiration. However, during PC ventilation, after the first half of inspiration, flow has virtually ceased and, therefore, almost no resistive pressure contribution is then present.

During PC ventilation, due to the constantly high pressure during inspiration, in comparison to the short

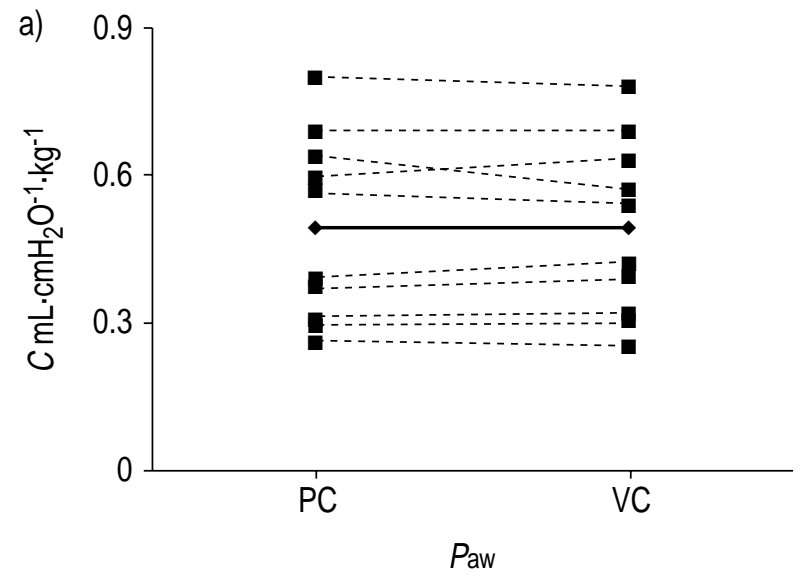

peak inspiratory pressure at the end of inspiration during $\mathrm{VC}$ ventilation (fig. 1), the time interval for air redistribution and stress relaxation in the inhomogeneous paediatric lung is longer. As in each method for analysis of respiratory system mechanics, the MLR method using the classical linear $R C$-model can only see and analyse an overall sum-signal from the entire lung, and not local contributions and inhomogeneities. Therefore, differences due to air redistribution should not have much effect on the respiratory mechanical indices determined by MLR. However, as the values for resistance and compliance are global, representing the whole respiratory system, there could be local parts with ongoing recruitment, and at the same time, overdistension of already open alveoli [23-25]. For analysis of nonlinear respiratory system mechanics, the equation of motion has been extended by a volume- and/or

b)

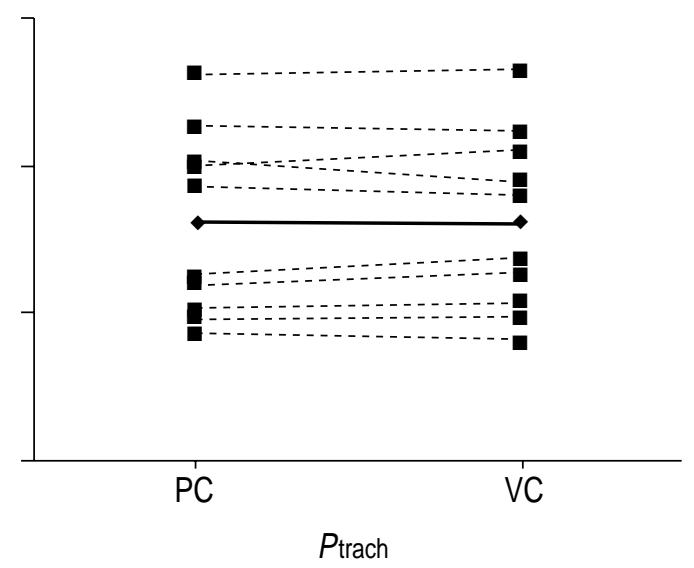

Fig. 3. - Differences in the determination of compliance during the different ventilator modes for individual infants. Symbols represent the mean out of 10 breaths. SD was generally less than $2 \%$ of the absolute value of respiratory system compliance $(C \mathrm{rs})$ and, therefore, is not shown. a) compliance is determined by multiple linear regression (MLR) based on airway pressure ( $P$ aw), thus including endotracheal tube (ETT); b) MLR is based on tracheal pressure ( $P$ trach), thus excluding ETT. CETT is small and can be neglected [21]. The bold lines indicate the mean values for all infants. PC: pressure controlled mode; VC: volume controlled mode. There is no statistically significant difference between the modes. 
flow-dependent elastance and/or resistance term $[8$, 26-28]. These approaches allowed new insights and understandings in the behaviour and modelling of the respiratory system.

Statistically significant differences in the respiratory mechanical indices, determined by MLR, between PC and VC ventilator modes were only found on resistance. Therefore, elimination of the flow-dependent resistance of the ETT did not alter these differences. These differences could be explained by the fact that during PC ventilation higher inspiratory peak flow rates occur than during $\mathrm{VC}$ ventilation, which results in a higher resistance of both the ETT and the respiratory system. Another likely explanation for these differences is the inspiratory flow pattern which is constant in the VC-mode, but varies from peak to zero in the PC-mode (fig. 1). Thus, the flow dependence is likely to have different characteristics and the algorithm may not apply equally well to both ventilator modes. However, although statistically significant, differences were small. Conversely, there are different sources for errors in daily routine monitoring of respiratory mechanics. Bearing in mind the respiratory set-up used at the bedside, in particular the sites where flow and pressure are measured (usually much closer to the ventilator, i.e. inside the ventilator, than to the patient, i.e. at the airway opening), the presence of a humidifier and the possibilities of kinking and obstruction of the ETT, it is assumed that relative errors in the determination of pulmonary mechanics in the range of $10 \%$ are clinically tolerable. Therefore, the clinician at the bedside may assume that analysis of dynamic respiratory system indices, $R \mathrm{rs}$, and $C$ rs, by MLR in paediatric patients is reliable and reproducible, and is mostly independent of the actual ventilator mode applied. Furthermore, for setting the ventilator according to dynamic $C \mathrm{rs}$ [7], it is important that there is no influence of the ETT or the ventilator mode on the determination of $C$ rs by MLR.

\section{Quality of fit}

The low RMS values indicate a good quality of fit. There was no improvement in the quality of fit after elimination of the flow-dependent resistance of the ETT. It is noteworthy that the mean RMS-value at VCmode indicates a slightly better quality of fit than that in PC-mode. A possible explanation is that in PC-mode with a decelerating flow profile, high volume acceleration occurs at the onset of inspiration and during the following nonlinear flow deceleration. Therefore, in PC ventilation, the mathematical model itself may be less appropriate and an additional term for volume acceleration (pressure contribution due to respiratory system inertance) may be necessary [29, 30]. In this context, it has to be assumed that the commonly used description of the respiratory system by the equation of motion, as previously described, is only appropriate during VC-ventilation. Nevertheless, a nonlinear approach [8, 26, 31, 32] would be appropriate and would probably improve the quality of fit, since in paediatric patients the respiratory system is known to be inhomogeneous and, therefore, highly nonlinear, particularly in disease.

\section{Limitations}

One drawback of this study is that it did not determine the functional residual capacity (FRC). Therefore, it cannot be excluded that the position on the static $P V$-curve shifted towards lower or higher FRC after the ventilator mode was changed and in consequence, the mechanical characteristics of the patient's lung changed. However, significant differences were found only in resistance and a change, predominantly in respiratory system compliance would have been expected, had there been a change in FRC [33].

Since the determination of ETT-coefficients for the calculation of tracheal pressure was performed in vitro for clean ETT, mucus inside the ETT after several days of mechanical ventilation may result in an undercorrection for the ETT in situ. However, throughout the daily ICU-routine and preceding each measurement, all patients were suctioned. After suctioning, for the relatively short period of investigation, no change in ETT patency was expected.

In summary, statistically significant differences were found in the determination of dynamic resistance between PC and VC modes. There was no statistically significant difference in the determination of dynamic respiratory system compliance. Differences in resistance remained after the mathematical elimination of the flow-dependent resistance of the ETT. In addition, there was no influence of the ETT on the determination of compliance. There was no effect on the quality of fit after the mathematical elimination of the flow-dependent resistance of the ETT.

In conclusion, using multiple linear regression for the determination of dynamic respiratory system mechanics compliance is independent of the actual ventilator mode, whereas there are small differences in resistance, possibly reflecting the different inspiratory flow patterns of the modes.

\begin{abstract}
Acknowledgements. The authors thank the Respiratory Therapy and Nursing staffs of the Paediatric Intensive Care Unit, Children's Hospital Los Angeles, for their assistance. The authors also gratefully acknowledge the support of A. Stenzler (SensorMedics, Yorba Linda, CA, USA) in providing equipment and export software, and M. Lichtwarck-Aschoff (Uppsala, Sweden and Augsburg, Germany), H. Pahl. (Freiburg, Germany) and G. Mols (Freiburg, Germany), for stimulating discussions and critical review of their manuscript.
\end{abstract}

\section{References}

1. Hammer J, Newth CJL. Infant lung function testing in the intensive care unit. Int Care Med 1995; 21: 744 752.

2. Newth C, Stretton M, Deakers T, Hammer J. Assessment of pulmonary function in the early phase of ARDS in pediatric intensive care. Pediatr Pulmonol 1997; 23: 169-175.

3. Patel NR, Hammer J, Nichani S, Numa A, Newth 
CJL. Effect of inhaled nitric oxide on respiratory mechanics in ventilated infants with RSV bronchiolitis. Int Care Med 1999; 25: 81-87.

4. Amato MBP, Barbas CSV, Medeiros DM, et al. Effect of a protective-ventilation strategy on mortality in the acute respiratory distress syndrome. $N$ Engl $J$ Med 1998; 338: 347-354.

5. Rosen WC, Mammel MC, Fisher JB, et al. The effects of bedside pulmonary mechanics testing during infant mechanical ventilation: a retrospective analysis. Pediatr Pulmonol 1993; 16: 147-152.

6. Fisher JB, Mammel MC, Coleman JM, Bing DR, Boros SJ. Identifying lung overdistension during mechanical ventilation by using volume-pressure loops. Pediatr Pulmonol 1988; 5: 10-14.

7. Mols G, Brandes I, Kessler V, et al. Volumedependent compliance in ARDS: proposal of a new diagnostic concept. Int Care Med 1999; 25: 1084-1091.

8. Nikischin W, Gerhardt T, Everett R, Bancalari E. A new method to analyze lung compliance when pressure-volume relationship is nonlinear. $\mathrm{Am}$ J Respir Crit Care Med 1998; 158: 1052-1060.

9. Lanteri CJ, Kano S, Nicolai T, Sly P. Measurement of dynamic respiratory mechanics in neonatal and pediatric intensive care: the multiple linear regression technique. Pediatr Pulmonol 1995; 19: 29-45.

10. Uhl RR, Lewis FJ. Digital computer calculation of human pulmonary mechanics using a least squares fit technique. Comput Biomed Res 1974; 7: 489-495.

11. Iotti GA, Braschi A, Brunner JX, et al. Respiratory mechanics by least square fitting in mechanically ventilated patients: applications during paralysis and during pressure support ventilation. Int Care Med 1995; 21: 406-413.

12. Seear M, Wensley D, Werner H. Comparison of three methods for measuring respiratory mechanics in ventilated children. Pediatr Pulmonol 1991; 10: 291-295.

13. Wall MA. Infant endotracheal tube resistance: effects of changing, length, diameter and gas density. Crit Care Med 1980; 8: 38-40.

14. Pérez-Pontàn JJ , Heldt GP, Gregory GA. Resistance and inertia of endotracheal tubes used in infants during periodic flow. Crit Care Med 1985; 13: 1052 1055 .

15. LeSouef PN, England SJ, Bryan AC. Total resistance of the respiratory system in preterm infants with and without an endotracheal tube. J Pediatr 1984; 104: 108-111.

16. Deakers TW, Reynolds G, Stretton M, Newth CJL. Cuffed endotracheal tubes in pediatric intensive care. J Pediatr 1994; 125: 57-62.

17. Guttmann J, Eberhard L, Fabry B, Bertschmann W, Wolff G. Continuous calculation of intratracheal pressure in tracheally intubated patients. Anesthesiol 1993; 79: $503-513$.

18. Guttmann J, Kessler V, Mols G, Hentschel R, Haberthür C, Geiger K. Calculation of intratracheal pressure in the presence of pediatric endotracheal tubes. A laboratory study. Crit Care Med 2000; 28: $1018-1026$.
19. Eberhard L, Guttmann J, Wolff G, et al. Intrinsic PEEP monitored in the ventilated ARDS patient with a mathematical method. J Appl Physiol 1992; 73: 479485.

20. Nicolai T, Lanteri C, Freezer N, Sly PD. Non-invasive determination of alveolar pressure during mechanical ventilation. Eur Respir J 1991; 4: 1275-1283.

21. Dorkin HL, Stark AR, Werthammer JW, Strieder DJ, Fredberg JJ. Respiratory system impedance from 4 to $40 \mathrm{~Hz}$ in paralyzed intubated infants with respiratory disease. J Clin Invest 1983; 72: 903-910.

22. Hickling KG. The pressure-volume curve is greatly modified by recruitment: a mathematical model of ARDS lungs. Am J Respir Crit Care Med 1998; 158: 194-202.

23. Jonson B, Svantesson C. Elastic pressure-volume curves: what information do they convey? Thorax 1999; 54: 82-87.

24. Svantesson C, Sigurdsson S, Larsson A, Jonson B. Effects of recruitment of collapsed lung units on the elastic pressure-volume relationship in anaesthetized healthy adults. Acta Anaesthesiol Scand 1998; 42: 1149-1156.

25. Peslin R, de Silva JF, Chabot F, Duvivier C. Respiratory mechanics studied by multiple linear regression in unsedated ventilated patients. Eur Respir J 1992; 5: 871-878.

26. Rousselot JM, Peslin R, Duvivier C. Evaluation of the multiple linear regression method to monitor respiratory mechanics in ventilated neonates and young children. Pediatr Pulmonol 1992; 13: 161-168.

27. Bersten AD. Measurement of overinflation by multiple linear regression analysis in patients with acute lung injury. Eur Respir J 1998; 12: 526-532.

28. Kano S, Lanteri CJ, Duncan AW, Sly PD. Influence of nonlinearities on estimates of respiratory mechanics using multilinear regression analysis. J Appl Physiol 1994; 77: 1185-1197.

29. Kessler V, Joerges S, Lichtwarck-Aschoff M, Mols G, Sjöstrand UH, Guttmann J. Respiratory system inertance and extravascular lung water in surfactant deficient piglets. Int Care Med 1999; 25: S6.

30. Kessler V, Ramirez J, Braun G, Mols G, Guttmann J. Respiratory system inertance investigation in a physical innertance model. Technol Health Care 2000; 8: 1-14.

31. Guttmann J, Eberhard L, Fabry B, et al. Determination of volume-dependent respiratory system mechanics in mechanically ventilated patients using the new SLICE method. Technol Health Care 1994; 2: 175-191.

32. Kessler V, Newth C, Guttmann J. Monitoring of nonlinear volume-dependent respiratory system parameters with the SLICE-method. Am Respir Crit Care Med 1999; 159: A777.

33. Burger R, Fanconi S, Simma B. Paralysis of ventilated newborn babies does not influence resistance of the total respiratory system. Eur Respir J 1999; 14: 357362. 